\title{
Geriatrik Cerrahide Güncel Yaklaşımlar
}

\author{
Fatma Sila AYAN*, Turgay DAĞTEKİN**
}

$\ddot{O} \mathbf{z}$

Fizyolojik yaşlanmanın biyolojik kayıplar ve atipik hastalık süreçleri adına yarattığı kimi riskler mevcuttur. Bu risklerin yönetilebilmesi adına cerrahi müdahaleler gerekebilmektedir. Geriatrik cerrahide hedefler kişinin sağlıklı ömür uzunluğunu, hayatta kalma süresini ve yaşam kalitesini olabildiğince uzatmaktır. Geriatrik cerrahi öncesinde, sırasında ve sonrasında diğer yaş gruplarında alınan önlemlere ek olarak planlanması gereken tedbirler ve düzenlemelerin güncel yaklaşımlar ve bilimsel kılavuzlar ışı̆̆ında incelenmesi gerekmektedir.

Anahtar Kelimeler: Geriatri, geriatrik cerrahi, yaşlı.

\section{Recent Approaches in Geriatric Surgery}

\begin{abstract}
Physiological aging creates several risks for biological losses and atypical processes. Surgical interventions may be required to manage these risks. The goals in geriatric surgery are to extend the person's healthy life span, survival time, and quality of life as much as possible. In addition to routine prohibitions, age-modified measures and arrangements should be planned preoperative and postoperative processes of the geriatric surgery in the light of current approaches and scientific guidelines.
\end{abstract}

Keywords: Geriatrics, geriatric surgery, elderly.

\footnotetext{
Derleme Makale (Review Article)

Geliş / Received: 05.06.2020 \& Kabul / Accepted: 05.11.2020

DOI: https://doi.org/10.38079/igusabder.748203

* Öğr. Gör., İstanbul Gelişim Üniversitesi, Sağlık Bilimleri Yüksekokulu, Gerontoloji Bölümü, İstanbul, Türkiye, E-posta: fsayan@gelisim.edu.tr ORCID https://orcid.org/o00o-0003-05761338

$\frac{1338}{* *}$ Dr. Öğr. Üyesi, İstanbul Gelişim Üniversitesi, Sağllk Bilimleri Yüksekokulu, Hemşirelik Bölümü, İstanbul, Türkiye, E-posta: tdagtekin@gelisim.edu.tr ORCID https://orcid.org/oooo0002-4138-1909
} 


\section{Giriş}

Dünyada gözlemlenen "gri tsunami” Türkiye’de de belirgin bir hale gelmiştir. Nüfusun yaklaşık \%9’u 65 yaşın üzerindedir . Fransa'nın 115 yılda geçirdiği demografik dönüşüm Türkiye'nin son 15 yıl civarında geçirdiği bir süreçtir. Bu durum dünyanın en hızlı yaşlanan ülkelerinden biri olmamızın yanında başta sağlık hizmetleri olmak üzere tüm hizmet süreçlerimizi yaşlı odaklı olarak güncellememizi gerektirmektedir ${ }^{2}$. İlgili başlıklardan birisi de geriatrik hasta grubuna cerrahi yaklaşımdır.

Yurtdışındaki veriler incelendiğinde geriatrik hasta grubunun tüm cerrahi prosedürlerin \%23'ünü oluşturduğu görülmektedir3. Ameliyat geçiren yaşlıların sayısı, genel popülasyondaki yaşlıların oranından daha hızlı bir şekilde artmaktadır ${ }^{4}$. Amerika'da 2025 yılına kadar nüfusun \%10'unun 75 yaşın üzerinde olması ve potansiyel olarak savunmasız olan bu grubun cerrahi bakım gerektireceği tahmin edilmektedir5. Bu durum geriatrik cerrahi hastalarının yönetiminde artan bir farkındalık ve cerrahi ilgi ile sonuçlanmıştır. Birçok yaşlı cerrahi hastası, hem elektif hem de acil cerrahi geçirirken yüksek morbidite ve mortalite riskine maruz kalmaktadır. Bunun nedeni uygulanan protokoller, hasta faktörleri veya her ikisi olabilmektedir. Risk faktörleri ve hastanın durumunun preoperatif olarak multidisipliner ve multimodal bir değerlendirme yoluyla tanımlanması, önceden var olan tıbbi koşulların ve uygun multidisipliner pre/perioperatif bakımın iyileştirilmesine olanak sağlamaktadır.

Tarihsel süreçte geriatrik hasta grubu için kontrendike saylan cerrahi müdahaleler günümüzdeki teknik ve teknolojideki tıbbi gelişmeler sayesinde çok daha sık ve güvenli bir şekilde uygulanabilmektedir. Buna karşın özgün özellik ve ihtiyaçlar sahip bir grup olmalarından dolayı geriatrik cerrahi hastalarının uygulanan müdahaleler, ameliyat öncesi ve sonrasındaki düzenlemeler, uzun süreli bakım imkânları, yaşam sonu direktifleri ve normal yaşama dönüş gibi konularda farklı bir odakla değerlendirilmesi gerekir. Bu derlemede geriatrik hastalara yönelik cerrahi operasyonlarda güncel yaklaşımlar, multidisipliner müdahale imkânları ve bireylerin yaşam kalitesini veya bağımsızlı̆̆ını sürdürmeyi amaçlayan gelişmeler aktarılarak alandaki uzmanlara gerontolojik ve psikososyal bakış açısıyla katkı sunulması amaçlanmaktadır. 


\section{Geriatrik Cerrahiye Karar Verme Süreci}

Geriatik hastalar atipik seyreden ve zincirleme krizler başlatabilen kimi sendromlarla karşı karşıya kalabilmektedir. Bu sorunların sevk ve idaresinde cerrahi müdahaleler gündeme geldiğinde karar vermek kolay olmayabilmektedir. Yaşlılıkla ilişkili fizyolojik kayıplar nedeniyle komplikasyon ve ölüm riskinin artması, iyileşme süresinin uzaması ve eşlik eden kronik hastalıklar çekinceler yaratsa da, hastanın insan onuruna yaraşır bir bakım alabilmesi, semptomatik acı, ağrı ve sıkıntılarının giderilebilmesi ve hatta kimi durumlarda hayatta kalabilmesi için bu müdahaleler zorunlu olabilir. Geriatrik hastalarda cerrahinin gerçekleştirilip gerçekleştirilmemesine yönelik karar verme sürecini etkileyen tutumlar kısaca şu şekilde karşılaştırılabilir6 ${ }^{6}$

Tablo 1: Geriatrik Hasta Grubunda Ameliyata Karar Verme Tutumları

\begin{tabular}{|c|c|}
\hline Ameliyat Lehine Tutum & Ameliyat Aleyhine Tutum \\
\hline $\begin{array}{l}\text { a) Hastanın ömrü uzatılabilir. } \\
\text { b) Benzer bir durumda olan } \\
\text { insanların çoğunluğu } \\
\text { muhtemelen tedaviyi kabul eder. } \\
\text { c) Beklenen yaşam kalitesinin, } \\
\text { tedavinin reddedileceği kadar } \\
\text { düşülk olup olmayacağını } \\
\text { belirlemenin bir yolu yoktur. }\end{array}$ & $\begin{array}{l}\text { a) Uzun süre hayatta kalma şansı düşüktür. } \\
\text { b) Bazı durumlarda ameliyat nispeten } \\
\text { ağrısız ölümün aksine, ağrı, transfüzyon, } \\
\text { entübasyon, pansuman gibi acı ve ıstırap } \\
\text { süreçlerine sebep olur. } \\
\text { c) Bağımlı veya karar verme yetilerinden } \\
\text { yoksun kişiler uzatılmış ve acı verici bir } \\
\text { yaşamı tercih etmeyebilirdi düşüncesi } \\
\text { kafa karıştırıcıdır. }\end{array}$ \\
\hline
\end{tabular}

Güncel veriler geriatrik hastaların cerrahi açıdan değerlendirilmesinde de diğer alanlarda olduğu gibi kapsamlı geriatrik değerlendirme verilerinin göz önüne alınması gerektiğini vurgulamaktadır5.

Geriatrik cerrahinin diğer alanlara göre özelleşen prensipleri şu şekilde özetlenebilir7:

1. Yaşlılarda cerrahi problemlerin klinik sunuşu, genel popülasyondakinden farklı olabilir. Bu, tanıda gecikmeye yol açabilir. 
2. Yaşlılar organ sistemi rezervi eksikliği nedeniyle ciddi düzeydeki stresi tolere edemezler. Bu sebeple ameliyat öncesi optimal hazırlık şarttır. Hazırlık yetersiz olduğunda perioperatif risk artar.

3. Yaşlılarda elektif cerrahinin sonuçları görece daha iyidir, acil cerrahinin sonuçları zayıf elektif cerrahiye göre daha zayıf olsa da genellikle riskten kaçınan ameliyat dışı tedaviden daha iyi çıktılar ortaya koyar.

4. Hastanın yaşı önyargıyla değil, bilimsel bir gerçek olarak ele alınmalıdır. Kronolojik yaş kendi başına, cerrahi işlemler için bir kontrendikasyon değildir.

5. İyi bir preoperatif ve perioperatif yaklaşım ile risklerin yönetilmesinde anlamlı sonuçlar alınabilir.

\section{Geriatrik Cerrahide Preoperatif ve Perioperatif Yaklaşımlar}

Geriatrik cerrahi için özgün yaklaşımlar 1960’lı yıllardan beri tartışılmakla birlikte kapsayıcı ve bütüncül kılavuzlara yeni yeni rastlanıldığı söylenebilir. Cerrahların ve geriatrik cerrahi sürecinde görevli diğer sağlık çalışanlarının aşağıda belirtilen güncel kılavuzlara hakim olması önem arz etmektedir. Bu başlıkta ameliyatına karar verilen geriatrik cerrahi hastasının preoperatif, perioperatif ve postoperatif değerlendirmesinde dikkat edilmesi gereken hususlar aktarılacaktır.

Geriatrik cerrahi hastasının preoperatif değerlendirmesinde, diğer yaş gruplarında olduğu gibi çok boyutlu bir bakış ve uzlaşı gerekmektedir. Bu açıdan laboratuvar değerlendirmesinde 60 yaş üzeri ve majör operasyon geçirecek tüm hastalarda tam kan sayımı istenmelidir. Hemoglobin takibi hemorajik komplikasyonların önlenmesinde referans konumundadır. Elektrokardiyografi (EKG) 50 yaş üzerindeki erkek ve 60 yaş üzerindeki kadınlarda rutin olarak istenmektedir. Buna ek olarak akciğer grafisi 60 yaş üzeri herkeste, kan üre düzeyi, serum kreatinini ve kan glukozu 40 yaşın üzerindeki herkeste istenmelidir. Buna ek olarak indikasyon durumuna göre serum albümin düzeyleri hastanın nutrisyonel durumunu özetlemesi ve yara iyileşmesini yorumlamaya yardımcı olması nedeniyle istenebilmektedir ${ }^{8}$.

Yaş anesteziye karşı direkt bir komplikasyon riski oluşturmamakla birlikte komorbiditeler, kırılganlık ve polifarmasi anestezistler adına kafa karıştırıcı durumlara 
sebep olabilmektedir. Minimum alveolar konsantrasyonun yaşla birlikte azalması sebebiyle hastaları etkileyecek inhaler anestetik dozu azalmaktadır. Kardiyak outputun fizyolojik yaşlanma sebebiyle azalması, volatil gazların etkisini arttırırken artan şantlar etkiyi azaltabilmektedir. Yaşla birlikte nöronal yoğunluğun ve vücut metabolizmasının azalması duyarlılığı arttırır. Küçük tekrarlayan dozlar ve yavaş infüzyon, bu duyarlılık durumunun ve yavaşlayan dolaşımın yan etkilerini azaltmak adına hayati önem taşır. Opiatlara artan duyarlılık postoperatif dönemde hipoksemiyi de tetikleyebilmektedir. Yapılan çalışmalarda spinal anestezi alan yaşlılarda genel anestezi alanlara kıyasla daha az mortalite, MI riski, transfüzyon ihtiyacı, solunum depresyonu ve emboli ve pnömoni insidansı gözlemlenmiştir ${ }^{9}$.

Kardiyak değerlendirmelerde genel olarak klinik belirteçler, fonksiyonel kapasite ve yapılacak cerrahinin tipi göz önüne alınır. Hastanın kan basıncının kontrol altında tutulması önemlidir. Klinik risk belirteçleri az olan ve düşük riskli cerrahi geçirecek olan yaşlılarda (yüzeyel, endoskopik, katarakt cerrahisi gibi operasyonlar) ileri tetkiklere gerek yoktur ancak orta ve üst düzey risk ve çok sayıda klinik risk belirteci olan hastalara da istirahat EKG'si, egzersiz stres testi ve egzersiz dışı stres testine bakılır ${ }^{10}$.

Pulmoner komplikasyonların önlenmesi adına yaşlının değerlendirilmesinde ameliyattan en az 8 hafta önce sigaranın bırakılması, malnütrisyonun önlenmesi ve obezite mevcutsa kilo verilmesi gerekmektedir. Ameliyattan 48-96 saat öncesinde rutin tedavilerin sürdürülmesi ve enfeksiyonların önlenmiş olması gerekmektedir. Hastaya solunum egzersizleri ile ilgili eğitimlerin verilmesi tavsiye edilmektedir. Anestezi sırasında atelektaziye karşı önlem alınması ve yoğun oksijen konsantrasyonlarından kaçınarak nemli ve ılık havalandırma yapılmalıdır ${ }^{11}$.

Geriatrik cerrahi hastanın ameliyat öncesindeki üç ay içinde \%10'dan fazla kilo değişimi olması, bu durumun fonksiyonel durumu etkileme olasılığı global değerlendirme skalaları ve Amerikan Parenteral ve Enteral Nütrisyon (ASPEN) kılavuzlarına göre değerlendirilmelidir ${ }^{12}$.

Cerrahi renal stres adına önemli bir stresördür. Primer ve sekonder yaşlanmanın, çoklu ilaç kullanımı ve fizyolojik kayıpların direkt ve dolaylı etkilerinin renal sistemdeki etkileri de göz önüne alınarak elektrolit dengesini temel girişimlerle sağlamak, gerektiği (ve 
uygun bulunduğu) durumlarda hastayı ameliyattan önceki 24 saat içinde diyalize almak veya eritropoietin dozunu arttırmak gibi önlemler planlanabilmektedir ${ }^{13}$.

Gastrointestinal sistem açısından rutin önlem ve izlemlere ek olarak yaşlının ameliyat öyküsü, sarılık ve kan transfüzyonu geçmişi, ilaç kullanımı, çabuk yorulma durumu, abdominal distansiyon gibi durumları sorgulanmalıdır. Halotan gibi hepatit yapabilecek anestetik ajanların yaşlıya uygunluğu dikkatli değerlendirilmelidir. Akut ülseri olan kişilerde elektif cerrahi ertelenmelidir. Gastroözefageal reflü öyküsü olan kişilerde nazogastrik tüp erken dönemde çekilecek şekilde planlamalar yapılmalıdır ${ }^{14}$.

Kanama riski bulunan majör girişimlerde hematolojik değerlendirme dikkatle yapılmalıdır. Preoperatif koagülasyon testleri anormalse, hasta öykü veremiyorsa, karaciğer hastalı̆̆ı, antikoagülan kullanımı, malabsorpsiyonu varsa operasyonun gerekliliği gözden geçirilmeli ve elzemse transfüzyon önlemleri ve parametrelerin ayrıntılı değerlendirilmesi ile gerçekleştirilmelidir ${ }^{15}$.

Diyabetik yaşlılarda elektif cerrahinin zamanlaması iyi planlanmalıdır. Oral hipoglisemik ajanların yaratabileceği uzamış etkiden korunmak adına oral antidiyabetikler en az 3 gün, kısa-orta etkili ajanlar ise en az 1-2 gün önceden kesilerek insülin tedavisine başlanmalıdır. Glisemik kontrolü iyi olmayan hastalarda enfeksiyon, yara iyileşmesinde gecikme, uzun süreli hospitalizasyon ve bakıma muhtaçlık, mortalite riskinin yüksek olduğu düşünülerek cerrahinin gerçekleştirme kararı iyi bir kar-zarar analizi sonucunda verilmelidir ${ }^{16}$.

Proaktif perioperatif bakım ekipleri, ameliyat edilen yaşlı hastalar için kişiselleştirilmiş bir koordine bakım yolu geliştirmeye yönelik çok yönlü bir yaklaşım sağlar ve böylece başarılı girişimlerin sayısını arttırdığı gibi sonuçları iyileştirir. Yapılan bir çalışmada bu yaklaşım sayesinde postoperatif elektif ortopedik hastalarda pnömoni ( $p=0,008)$, yara enfeksiyonu $(\mathrm{p}=0,004)$ ve bası yaralarında $(\mathrm{p}=0,028)$ istatistiksel olarak anlamlı bir azalma gözlemlenmiştir ${ }^{17}$.

Postoperatif süreçte yara iyileşme tepkisinin yaşlılarda genç bireylere göre değiştiği açıktır. Enflamasyon, anjiyogenez, epitelizasyon ve yeniden modelleme süreçlerinin her birinde ve nihayetinde yara iyileşmesini genel olarak bozabilecek değişiklikler gözlemlenir. Bununla birlikte, komorbiditesi ve kırılganlığı olmayan yaşlılarda bu değişimin diğerlerine kıyasla minimal olduğu söylenebilir. Kollajen metabolizması gibi 
bazı yara iyileşme süreçleri hakkında kesin sonuçlara varmak hala zordur ancak bazı hastalık durumları (yetersiz beslenme, enfeksiyonlar, hipoksi ve yeniden oksijenlenme, diyabet ve ilaç etkileşimleri) ile yaş arasında açık bir ilişki gözlenmektedir. Bu durumdaki hastalar dikkatle değerlendirilmeli ve büyüme faktörleri ve besin takviyeleri ile desteklenmelidir ${ }^{18}$.

\section{Geriatrik Cerrahide Postoperatif Sürecin Planlanması ve Palyatif Bakım}

Palyatif bakım, hastalar ve aileleri için yaşam kalitesini artırmak amacıyla ağrı yönetimi ve tedavi edilemeyen kronik tabloların diğer ilerleyici semptomlarını hafifletmek için gerçekleştirilen multidisipliner müdahalelere atıfta bulunur ${ }^{19}$.

Literatürde yer alan birçok çalışma palyatif bakımın yaşam kalitesini artırdığı ve bazen hayatta kalmayı geliştirdiğini bulgulamaktadır ${ }^{20,21}$. Bu faydalara ek olarak palyatif bakım, hastane içindeki mortalite oranlarını sınırlamak, hospitalizasyon süresini azaltarak maliyetleri azaltmak gibi birçok ikincil katkı sunmaktadır²2-25.

Palyatif bakım sanılanın aksine sadece semptomların hafifletilmesine odaklanmak veya yalnızca yaşam sonu bakımı ile sınırlı değildir. Palyatif bakım, ciddi bir hastalığın tüm tedavi sürecini kapsayabilir ve hastaneler, ayakta tedavi klinikleri ve bakımevleri gibi ortamlarda çeşitli sağlayıcılar tarafından sunulabilir. Palyatif bakım uygulamalarının tanımları ve palyatif bakıma ihtiyacı olan hastaların nasıl belirleneceği aşağıdaki tabloda kısaca açıklanmıştır ${ }^{26}$.

Tablo 2: Palyatif Bakım Hizmetlerinin Tanımlanması

Palyatif Bakım Hizmetlerinin Tanımlanması ve Hastaların Değerlendirildiği Alanlar

1. Palyatif bakım: Ağrı ve diğer semptomlardan kurtulma sağlayan, yaşam kalitesini destekleyen ve ileri düzeyde ciddi ve/veya kronik hastalığı olan hastalara ve ailelerine odaklanan bakım.

2. Temel palyatif bakım: Birinci basamak klinisyenler gibi sağlık uzmanları tarafından verilen palyatif bakım; hastalığa yönelik uzman doktorlar (onkologlar ve kardiyologlar gibi); hemşireler, gerontologlar, sosyal hizmet uzmanları, eczacılar, din görevlileri ve palyatif bakım sertifikası olmayan ancak temel bakım hizmetlerini veren teknikerler/bakımverenler. 
3. Uzmanlık alanı olarak palyatif bakım: Palyatif bakım uzmanı olan sağlık çalışanları tarafından verilen ve bu alanda geçerli eğitim veya sertifikaları olan hekimler, gerontologlar, hemşireler, sosyal hizmet uzmanları, eczacılar ve din görevlilerinin ayrıntılı bir planla bütüncül olarak verdiği hizmet.

4. Yaşam sonu bakımı: Ölüme yaklaşan kişilerin tıbbi, sosyal, duygusal ve ruhsal ihtiyaçlarını karşılama sürecidir. Hastalıklara özgü müdahalelerin yanı sıra, yaşamın sonuna yaklaşmış olan ileri derecede ciddi rahatsızlıkları olanlara palyatif ve hospis bakımı da dahil olmak üzere bir dizi tıbbi ve sosyal hizmet girişimleri içerebilir.

5. Hospis: Genellikle en fazla 6 ay yaşam beklentisi olan kişilere deneyimledikleri terminal süreci fiziksel ve duygusal olarak daha rahat hale getirmek amaciyla, profesyoneller ve diğer bakıcıların işbirliği ile tıbbi, hemşirelik, sosyal, psikolojik, duygusal ve manevi hizmetler sunmak için disiplinlerarası bir yaklaşımın sunulduğu merkezlerdir. $\mathrm{Bu}$ kurumlarda hastaların son istekleri yerine getirilmeye çalışılır, ailelerin konaklayabileceği özel alanlar vardır ve vefatın ardından yas danışmanlığı verilir.

6. Bakım hedefleri: Mevcut hastalık(lar), prognoz ve tedavi seçeneklerinin bilinçli bir şekilde tartışılmasından sonra ortaya çıkan fiziksel, sosyal, manevi veya diğer hasta merkezli hedeflerin ve hangi hasta gruplarının bu bakım türlerinin hangisine uygun olduğunun belirlenmesidir.

a. Sosyal ve manevi ihtiyaçlar: Hastanın günlük yaşamın etkileyen sosyal ve manevi örüntüler ve talepler var m??

b. Hastahk ve süreç ile ilgili bilgi: Hasta ve ailesinin hastalık ve prognoz ile ilgili net ve tam bilgisi ve planı var m??

c. Bakımin hasta odakh hedefleri nelerdir? Hasta / ailesi / temsilcisi tarafindan belirlenen bakım hedefleri nelerdir? Tedavi seçenekleri ve aydınlatılmıs onamlar hasta merkezli hedeflerle eşleşiyor mu? Hasta uzun süreli bakımın planlama sürecine katıldı mi/katılabildi mi? Hedefler ve direktifler kâğıt üzerinde belgelendi mi?

Geriatrik hastalarda ameliyat kararı verilirken cevaplanması gereken dört temel soru ameliyatın gerekliliği, her şeyin çok iyi gittiği bir senaryoda kazanılacaklar, her şeyin kötü gittiği bir senaryonun olasılığı ve bu durumda neler yapılabileceğidir ${ }^{26}$. Amerikan Anestezistler Derneği (ASA) sınıflandırması, fonksiyonel durum, sepsis ve yaşın mortalite ile anlamlı derecede ilişkili olduğunu belirten bir çalışma gerçekleştirmiştir. Bu 
çalışmada, ameliyat olmazsa hayatta kalamayacağı düşünülen ASA V. düzey hastalarda (rüptüre karın/ torasik anevrizma, masif travma, kitle etkisi ile kafa içi kanama, belirgin kardiyak patoloji veya çoklu organ/ sistem disfonksiyonu karşısında iskemik bağırsak), 90 yaş ve üzeri hastalarda sağ kalım olasılığı \%10'dan daha azdır²7,28. Akut hastalıklarda sağ kalan yaşlılarda bile, acil durum prosedürleri yüksek komplikasyon oranları ile ilişkilidir. Sağ kalımın sağlanabildiği durumlarda dahi ameliyat sonrasında kritik fonksiyonel kayıpların gözlemlendiği söylenebilmektedir. Açık aort anevrizması onarımı yapılan 80-89 yaş aralığındaki yaşlıları araştıran bir çalışmada, hastaların \% 40'ının "tatmin edici bir fonksiyonel bağımsızlık düzeyi” ile eve döndüğü ancak her hastanın ameliyat öncesine kıyasla ameliyat sonrasında destekli yaşam alternatiflerine ihtiyaç duymalarına neden olabilecek fonksiyonel kayıplar yaşadığı gözlemlenmiştir.

Geriatrik cerrahi, gerek kar zarar oranı ile iyileşmeyi gerekse uzun süreli veya yaşam sonu bakımında palyasyon amacıyla değerlendirilirken tüm durumlarda önceliğin bireysel kırılganlık seviyesini, semptomları, prosedürün başarı ve dayanıklılığını, cerrahi olmayan tedavinin kullanılabilirliği ve etkinliğini ve hastanın yaşam kalitesini ve beklentisini dikkate almalıdır.

\section{Geriatrik Cerrahide Etik Konular}

Yaşlılarda cerrahinin amacı, hastanın maksimum yaşam beklentisine ulaşma şansını artırmak veya gereksiz risk almadan hayatını daha rahat hale getirmektir. Bu hedefe yönelik kararlar genellikle birincil açıdan tıbbidir ve mortalite oranı, şiddetli semptomların giderilmesinde başarı veya alternatif tedavi olasılığı gibi hesaplanabilir konuları kapsar. Daha derin ve çok daha karmaşıktır konular ise, tıbbi kararların geçerliliğini belirleyen konumdadır ve geleneksel tıp düşüncesi ile sınırlandırılamaz. Yaşam kalitesi, onurlu bir ölüm, maliyet, hizmetlerin yetersiz olduğu durumlarda hastanın özgür seçimi gibi konular gündeme gelmektedir ve bu konuda net kural ve doğrular bulunmamakla birlikte kırılgan kişileri korumak adına kimi yaklaşımlar söz konusudur.

Bu kişisel ve sosyal kavramlara ek olarak sağlık sektörü ve çalışanlarındaki kimi düşünsel şemalar ve önyargılar da geriatrik cerrahideki etik ikilemleri tetikleyebilmektedir. Bunlardan bazıları şu şekilde sıralanabilir29:

a) Malpraktis korkusu. 
b) Özellikle genç cerrahlarda görülebilen daha fazla operasyon gerçekleştirme tutumu.

c) Zorlayıcı operasyonların getirdiği motivasyon ve hırs.

d) Hastaları olabildiğince uzun süre hayatta tutabilmeyi en öncelikli plana alırken zarar vermeme ilkesi ile çelişkiye düşülmesi.

e) Yaşıının, cerrahın/sağlık çalışanının kendi yaşı hakkındaki korkularını uyarması.

f) Yaşlı hastalar ve cerrah arasında ebeveyn figürlerine benzer bir çatışmanın vuku bulmasi.

g) Sağlık çalışanının tedavi ve verilen emeği nafile ve karşllıksız görmesi ve yaşlının sağlık sorunlarını primer yaşlanmanın doğasına indirgemesi.

Koruyucu sağlık hizmetlerinin dördüncül koruma tanımlaması ile birlikte hastaların sağlık çalışanlarının zarar vermesinden; defansif ve ofansif tıp yaklaşımlarından ve iyatrojenik zararlardan korunması adına genişletildiği bilinmektedir. Bu durum geriatrik hasta grubunda cerrahi müdahalelerin yapılıp yapılmaması, müdahalenin sonuçları veya hastanın hür seçimlerinin nasıl koruma altına alınacağı gibi soruları doğurmaktadır. Nazbony ve arkadaşlarının yaptığı çalışmalara göre cerrahların bakış açısına göre ameliyat kararı ve mücadeleye devam edip etmeme kararı, doktorun geçmiş deneyimlerinden büyük ölçüde etkilenir. Yaşlı bir hasta üzerinde varsayımsal bir yüksek risk prosedürü tartışan cerrahların katılımcısı olduğu odak grup görüşmelerinde "bazı cerrahların geriatrik grupta genellikle iyi bir sonuç alma olasılığının çok küȩük olduğuna ve tedavi yüklerinin çok yüksek olduğuna inandıkları ve hastaya/ailesine ameliyatı teklif dahi etmeyeceği" ifade edilirken grubunun kalanındaki kimi cerrahların "hasta/aile ısrar ederse ameliyatı önerebileceklerini ve yapacaklarını, ancak karar verme aşamasındaki görüşmede ameliyata karşı önyargı sağlayacak şekilde çerçeveledikleri bir görüşme yapacaklarını" vurgulamıştırº.

Geriatrik tıbbın ve cerrahinin sağlık çalışanının yaklaşımı ve bilgisinden bağımsız etik konu başlıkları hastanın bilgi edinme hakkı, aydınlatılmış onam, tedaviyi reddetme hakkı ve ileri düzey bakım konularının planlanmasına katılım gibi bileşenlerden oluşur ${ }^{3}$. Bilimsel bilgiler ışığında tedavi alternatifleri ve medikal karar verme süreçlerinde yaşlı hastaların hakları ve özgürlüklerini korumak adına özgün modellerin de ortaya koyulduğu ve kullanıldığı bilinmektedir. "Geriatriye Duyarlı Karar Verme Modeli" hastanın yaşam öyküsünü, önceliklerini, tercihlerini, algılanan yaşam kalitesini, onurlu 
bir ölüm hakkını göz önüne alır. Bu açıdan güvene dayalı, açık ve basit bilgilerin aktarılmasının ardından alternatifler objektif bir şekilde sunulmalı ve hasta ile uzlaşı içinde olunmalıdır.

Yurtdışı literatüründe yaşlı hastanın ileri yaşam direktifleri olarak anılan ötenazi ve Do Not Resuscitate (DNR) kararının perioperatif ve postoperatif süreçteki boyutuna yönelik çok sayıda çalışma bulunmaktadır. Bu çalışmaların sonuçlarına göre hastanın karar verme yetisinin değerlendirilmesi, karar verebilecek durumda bulunan hastalarda izlenecek süreç ve karar veremeyecek durumda/otonomisi olmayan hastalarda yasal vasilerinin görüşleri tartışılırken ülkemizde bu alanda daha fazla çalışmaya ihtiyaç duyulduğu görülmektedir. Geriatrik cerrahinin ve genel olarak medikal etiğin önemli bir bileşeni olan bu konu ülkemizdeki yasal çerçeveler sebebiyle kısıtlanan, toplumdaki farkındalık seviyesinin oldukça düşük olduğu ve genel olarak hekimin inisiyatifine bırakılan bir konumdadır. Bu sebeple etik bir soru işareti ve tartışma konusu olarak gerontolojik bakım ve geriatrik cerrahideki güncel çalışma konularından biri olarak seçilebileceği düşünülmektedir. İlerleyen yıllarda seçim hakkını destekleyecek ve insan haklarına duyarlı düzenlemelerin yapılması adına dünyada tartışılan farklı dayanak, görüş, yasa ve örneklerden yararlanılması beklenmektedir.

Karar verme sürecinden yaşlının öldükten sonra da onurunu korumaya uzanan süreçte unutulmaması gereken nokta klinik gerontoloji ve geriatrinin ana hedefinin cerrahide de uygulanmasıdır: "Mümkün olduğu sürece tedavi et, sıklıkla rahatlat, daima önemse ve istikrarlı bir bakım ver" 32,33 .

\section{Sonuç}

Biyopsikososyal açıdan yaşlılık ve yaşlanma süreçlerine uygun olarak yeniden tasarlanması gereken geriatrik cerrahi hizmetlerinde ana hedef kayıları geri döndürmek, geri döndürülemeyecek kayıplarda ise kaliteli ve ağrıdan uzak bir yaşam firsatı sunabilmektir. Geriatrik cerrahi süreci planlanırken hastanın fizyolojik kayıplarına, çoklu kronik hastalıklarına, ilaç kullanımına, tercih, görüş ve sosyokültürel özelliklerine saygı duyulmalıdır. Dördüncül koruma ilkelerine uygun bir şekilde hastanın yaşamsal risklerden, yaş ayrımcısı tutum ve önyargılardan, gereksiz acı ve ağrılardan korunması gerekmektedir. 


\section{KAYNAKLAR}

1. Türkiye İstatistik Kurumu. Nüfus Projeksiyonları, 2018-2080. TÜİK. http://www.tuik.gov.tr/PreHaberBultenleri.do?id=30567. Yayınlanma tarihi Şubat 2018. Erişim tarihi 04 Haziran 2020.

2. Tufan İ. Türkiye'de Sosyal ve Uygulamalı Gerontolojinin Tarihsel Temelleri. In: Durak M ve Tufan İ. Gerontoloji 1. İstanbul: Nobel;2017.

3. Office for National Statistics. Estimates of the very old (including Centenarians): England and Wales, and United Kingdom, 2002 to 2014. Office for National Statistics.

http://www.ons.gov.uk/peoplepopulationandcommunity/birthsdeathsandmarr iages/ageing/bulletins/estimatesoftheveryoldincludingcentenarians/2015-0930. Yayınlanma tarihi Eylül 2015. Erişim tarihi 04 Haziran 2020.

4. Etzioni DA, Liu JH, Maggard MA, et al. The aging population and its impact on the surgery workforce. Ann Surg. 2003;238:170-177.

5. Pearce L, Bunni J, McCarthy K, Hewitt J. Surgery in the older person: training needs for the provision of multidisciplinary care. Ann R Coll Surg Engl. 2016;98(6):367-370. doi:10.1308/rcsann.2016.0180.

6. Reiss R. Moral and ethical issues in geriatric surgery. $J$ Med Ethics. 1980;6(2):71-77. doi:10.1136/jme.6.2.71.

7. Katlic MR. Principles of Geriatric Surgery. In: Rosenthal RA, Zenilman ME, Katlic MR. Principles and Practice of Geriatric Surgery. 2nd ed. New York: Springer; 2011.

8. Aydın K, Arığul S. Geriatrik Populasyonda Perioperatif Değerlendirme. In: Sarığul S. Geriatri ve Gerontoloji. Ankara: MN Medikal ve Nobel Ltd. Şti; 2006.

9. Prins MH, Hirsh J. A comparison of general anesthesia and regional anesthesia as a risk factor for deep vein thrombosis following hip surgery: a critical review. Thromb Haemost. 1990;64(4):497-500. 
10. Wijeysundera DN, Naik JS, Beattie WS. Alpha-2 adrenergic agonists to prevent perioperative cardiovascular complications: a meta-analysis. Am J Med. 2003;114(9):742-752. doi:10.1016/sooo2-9343(03)o0165-7

11. Wilson SH, Fasseas $\mathrm{P}$, Orford JL, et al. Clinical outcome of patients undergoing non-cardiac surgery in the two months following coronary stenting. $J$ Am Coll Cardiol. 2003;42(2):234-240. doi:10.1016/s0735-1097(03)00622-3

12. Corish CA. Pre-operative nutritional assessment in the elderly. J. Nutr. Health Aging. 2001;5:49-59.

13. Eikelboom JW, Quinlan DJ, Douketis JD. Extended-duration prophylaxis against venous thromboembolism after total hip or knee replacement: a metaanalysis of the randomised trials. Lancet. 2001;358(9275):9-15. doi:10.1016/So140-6736(oo)05249-1

14. Turpie AG, Bauer KA, Eriksson BI, Lassen MR. Fondaparinux vs enoxaparin for the prevention of venous thromboembolism in major orthopedic surgery: a meta-analysis of 4 randomized double-blind studies. Arch Intern Med. 2002;162(16):1833-1840. doi:10.1001/archinte.162.16.1833

15. Sandham JD, Hull RD, Brant RF, et al. A randomized, controlled trial of the use of pulmonary-artery catheters in high-risk surgical patients. $N$ Engl $J$ Med. 2003;348(1):5-14. doi:10.1056/NEJMoa021108

16. Khadka R, Tian W, Hao X, Koirala R. Risk factor, early diagnosis and overall survival on outcome of association between pancreatic cancer and diabetes mellitus: changes and advances, a review. Int J Surg. 2018;52:342-346. doi:10.1016/j.ijsu.2018.02.058

17. Harari D, Hopper A, Dhesi J, et al. Proactive care of older people undergoing surgery ('POPS'): designing, embedding, evaluating and funding a comprehensive geriatric assessment service for older elective surgical patients. Age Ageing. 2007;36:190-196.

18. Marti GP, Liu L, Zhang X, et al. Wound Healing in the Elderly. In: Rosenthal RA, Zenilman ME, Katlic MR. Principles and Practice of Geriatric Surgery. 2nd ed. New York: Springer; 2011. 
19. Committee on Approaching Death: Addressing Key End of Life Issues; Institute of Medicine. Dying in America: Improving Quality and Honoring Individual Preferences Near the End of Life. Washington (DC): National Academies Press (US); 2015 .

20. Casarett D, Johnson M, Smith D, et al. The optimal delivery of palliative care: a national comparison of the outcomes of consultation teams vs inpatient units. Arch Intern Med. 2011;171(7):649-55.

21. Temel JS, Greer JA, Muzikansky A, et al. Early palliative care for patients with metastatic non-small-cell lung cancer. N Engl J Med. 2010;363(8):733-42.

22. Yoo JW, Nakagawa S, Kim S. Integrative palliative care, advance directives, and hospital outcomes of critically ill older adults. Am J Hosp Palliat Care. 2012;29(8):655-662.

23. May P, Garrido MM, Cassel JB, et al. Cost analysis of a prospective multi-site cohort study of palliative care consultation teams for adults with advanced cancer: where do cost-savings come from? Palliat Med. 2017;31(4):378-386.

24. Ciemins EL, Blum L, Nunley M, et al. The economic and clinical impact of an inpatient palliative care consultation service: a multifaceted approach. J Palliat Med. 2007;10(6):1347-1355.

25. May P, Normand C, Morrison RS. Economic impact of hospital inpatient palliative care consultation: review of current evidence and directions for future research. J Palliat Med. 2014;17(9):1054-1063.

26. Ballou JH, Brasel KJ. Palliative care and geriatric surgery. Clin Geriatr Med. 2019;35(1):35-44. doi:10.1016/j.cger.2018.08.004

27. American Society of Anesthesiologists. ASA Physical Status Classification System. ASA. https://www.asahq.org/standards-and-guidelines/asa-physicalstatus-classification-system. Yayınlanma tarihi Ekim 2019. Erişim tarihi 04 Haziran 2020.

28. Al-Temimi MH, Griffee M, Enniss TM, et al. When is death inevitable after emergency laparotomy? Analysis of the American College of Surgeons National 
Surgical Quality Improvement Program database. J Am Coll Surg. 2012;215(4):503-11.

29. Lewis MC, Yeldo NS. The ethics of surgery at end of life. Anesthesiol Clin. 2019;37(3):561-571. doi:10.1016/j.anclin.2019.04.005

30. Nabozny MJ, Kruser JM, Steffens NM, et al. Constructing high-stakes surgical decisions: it's better to die trying. Ann Surg. 2016;263(1):64-70.

31. Zenilman ME. Ethical Considerations. In: Rosenthal RA, Zenilman ME, Katlic MR. Principles and Practice of Geriatric Surgery. New York: Springer; 2000.

32. Jahnigen DW. Interacting with the Elderly Patient, Family, and Referring Physicians. In: Rosenthal RA, Zenilman ME, Katlic MR. Principles and Practice of Geriatric Surgery. New York: Springer; 2000: Chapter 9.

33. Tufan İ. Gerontoloji Meslek Yemini. In: Gerontoloji Ödülleri Açılış Konuşması; 2016; Dinar, Türkiye. 